\title{
Interstate Protectionism: The Case of Solar Renewable Energy Credits
}

Jed J. Cohen

Johannes Kepler University

Levan Elbakidze

West Virginia University

Randall Jackson

West Virginia University

Follow this and additional works at: https://researchrepository.wvu.edu/rri_tnc

Part of the Regional Economics Commons

\section{Recommended Citation}

This is a preprint of the article. Please cite the published version found on the journal website. Cohen, Jed J., Levan Elbakidze, Randall Jackson. 2021. "Interstate Protectionism: The Case of Solar Renewable Energy Credits." American Journal of Agricultural Economics 1-22. https://doi.org/10.1111/ ajae.12248

This Article is brought to you for free and open access by the Funded Research Reports at The Research Repository @ WVU. It has been accepted for inclusion in The Nature Conservancy by an authorized administrator of The Research Repository @WVU. For more information, please contact ian.harmon@mail.wvu.edu. 


\title{
Regional Research Institute West Virginia University
}

Research Paper Series

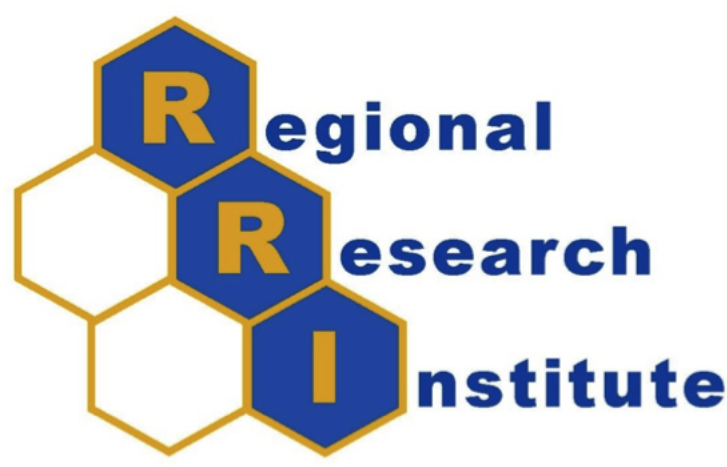

Interstate Protectionism:

The Case of Solar Renewable Energy Credits

\begin{abstract}
JED J. COHEN
Corresponding Author, Energy Institute at Johannes Kepler University

LEVAN ELBAKIDZE

Division of Resource Economics and Management and the Center for Innovation in Gas Research and Utilization, West Virginia University

RANDALL JACKSON

Geology and Geography Department and Regional Research Institute, WEST VIRGINIA UNIVERSITY
\end{abstract}

Date Submitted: August 10, 2020

Keywords: RPS, Solar Energy, Renewable Energy Credits, Interstate Trade, Protectionism JEL Classification: H77, Q42, Q48 


\title{
Interstate Protectionism: The Case of Solar Renewable Energy Credits
}

\author{
Jed J. Cohen* \\ Levan Elbakidze† \\ Randall Jackson $\ddagger$
}

August 10, 2020

\begin{abstract}
Solar Renewable Energy Credits (SRECs) are financial instruments created by state policies to offer incentives for generating solar energy. In an effort to support in-state solar energy sectors and boost local employment opportunities, some states have closed off their SREC markets to out-of-state solar facilities. We examine the merits of such protectionist policy from the protectionist states perspective. We find that SREC market closure leads to higher in-state SREC prices, greater solar installation, and lower electricity prices. The study illustrates the economic incentives for protecting in-state SREC markets from out-of-state solar energy producers.
\end{abstract}

\section{Recommended Citation}

This is a preprint of the article. Please cite the published version found on the journal website.

Cohen, Jed J., Levan Elbakidze, Randall Jackson. 2021. "Interstate Protectionism: The Case of Solar Renewable Energy Credits." American Journal of Agricultural Economics 1-22. https://doi .org/10.1111/ ajae. 12248

*Corresponding Author, Energy Institute at Johannes Kepler University

$\dagger$ Division of Resource Economics and Management and the Center for Innovation in Gas Research and Utilization, West Virginia University

$\ddagger$ Geology and Geography Department and Regional Research Institute, West Virginia University 


\section{Acknowledgements}

The authors gratefully acknowledge funding for this research from The Nature Conservancy West Virginia branch.

(C)This manuscript is made available under the CC-BY-NC-ND 4.0 license. 
$<$ This page blank $>$ 


\title{
Interstate Protectionism: The Case of Solar Renewable Energy Credits
}

\author{
Jed J. Cohen ${ }^{1}$, Levan Elbakidze ${ }^{2}$ and Randall Jackson ${ }^{3}$ \\ Aug. 10th, 2020 \\ ${ }^{1}$ Corresponding Author \\ Energy Institute at Johannes Kepler University. Altenbergerstrasse 69, Linz, Austria \\ 4040 \\ email: cohen@energieinstitut-linz.at \\ ${ }^{2}$ Division of Resource Economics and Management and the Center for Innovation in Gas \\ Research and Utilization at West Virginia University. 4100 Ag. Sciences Bldg., \\ Morgantown, WV 26506 \\ email: levan.elbakidze@mail.wvu.edu \\ ${ }^{3}$ Geology and Geography Department and Regional Research Institute at West Virginia \\ University. 886 Chestnut Ridge Road, Morgantown, WV 26506 \\ email: randall.jackson@mail.wvu.edu
}

\section{Acknowledgements}

The authors gratefully acknowledge funding for this research from The Nature Conservancy West Virginia branch.

\section{Citation Information}

This is a preprint of this article. For the final version please see "Interstate Protectionism: The Case of Solar Renewable Energy Credits" published in the American Journal of Agricultural Economics, 2021. Please cite the published version found on the journal website.

(C)2020 This manuscript is made available under the CC-BY-NC-ND 4.0 license 


\begin{abstract}
Solar Renewable Energy Credits (SRECs) are financial instruments created by state policies to offer incentives for generating solar energy. In an effort to support in-state solar energy sectors and boost local employment opportunities, some states have closed off their SREC markets to out-of-state solar facilities. We examine the merits of such protectionist policy from the protectionist states perspective. We find that SREC market closure leads to higher in-state SREC prices, greater solar installation, and lower electricity prices. The study illustrates the economic incentives for protecting in-state SREC markets from out-of-state solar energy producers.
\end{abstract}

Keywords: RPS; Solar energy; Renewable Energy Credits; Interstate Trade; Protectionism

\title{
1 Introduction
}

In the U.S., a cohesive renewable energy policy at the national level remains elusive, inducing states to craft disconnected energy policies. Many of these policies take the form of renewable portfolio standards (RPS) that require a minimum renewables' share of electricity generation and can offer a cost effective alternative to cap and trade or carbon tax regulations (Goulder et al., 2016). States may consider including protectionist measures in their energy policies to ensure that the benefits from these policies stay within the state. We analyze the economic case for interstate protectionism in RPS policies that include Solar Renewable 
Energy Credit (SREC) markets. In particular, we are interested in evaluating the market host state's incentives to close the market to out-of-state actors. Closing the market may increase in-state investment and employment opportunities in the solar industry. However, closing SREC markets can increase RPS compliance costs, potentially creating a negative impact on electricity rate payers. A Quasi-experimental set-up with some states recently closing their SREC markets to out-of-state actors allows for identifying the effects on SREC prices, solar installations, and electricity prices from market protectionism.

SRECs are financial instruments that are granted to producers of solar power when they generate electricity from solar sources in certain states and under certain conditions. SRECs exist due to state RPS laws that include a 'solar carveout', which requires that a specific percentage of generated power comes from solar generation sources. In states with such RPS laws, utility companies are required to meet a solar carve-out requirement either through producing their own solar power or by purchasing SRECs on open markets and 'retiring' the purchased credits with the state regulator. Only states that have enacted a solar carve-out have SREC markets, and only the utilities in these states must satisfy the solar requirement.

SRECs are meant to provide financial support to owners of solar generation facilities and provide additional incentive to install solar technology. The standards that must be met for a solar facility to qualify for a state's SREC program vary by state and are determined by the legislation that set up the solar carve-out. Some states only allow in-state solar facilities to qualify for their SREC market, 
while other states allow facilities in surrounding states to qualify as well. The effects of the interstate trade of SRECs on solar installation rates, or the lack thereof when regulations prohibit such trade, is the subject investigated herein. The primary contribution of our research is to better understand the merits of restricting interstate SREC trade. In particular, does restricting out-of-state SRECs lead to greater in-state solar adoption? Does the restriction increase SREC and electricity prices?

States enact protectionist SREC market laws in response to falling SREC prices and claims that out-of-state solar power producers are benefiting from state funding while state residents and utility companies bear the cost of the regulation. Restricting the sale of out-of-state SRECs may increase SREC prices and the incentive to install solar panels. A primary argument for market protectionism is to protect or create in-state solar industry jobs and keep the investments in solar energy within the state's own economy (Schmalensee, 2011).

The subject of interstate protectionism in SREC markets is of interest from both economic and legal perspectives. From the economic perspective, the enactment of protectionist policies by some of the RPS states with solar carve-outs serves as a quasi-experiment in state SREC markets enabling an assessment of associated economic consequences. From a legal perspective, the discussion is ongoing regarding the constitutionality and ramifications of interstate protectionism in electricity markets. Specifically, state laws that discriminate against goods and services from other states may be illegitimate under some interpretations of the Commerce Clause of the U.S. Constitution. This may apply to RPS and solar 
carve-out standards (Griffin, 2014; Havemann, 2012) ${ }^{1}$.

The issue of interstate protectionism in SREC markets, and more broadly in RPS standards with Renewable Energy Credit (REC) provisions ${ }^{2}$, has been explored at length in the policy and legal literature (e.g. Griffin, 2014; Havemann, 2012; Glickstein, 2013; Elefant and Holt, 2011; Ferrey, 2004; Engel, 1999). Glickstein (2013) writes, "It is clear from observing the markets in every state that allowing out-of-state participation in a SREC market is flawed policy" (pg. 1273). Other state policy experts discuss the possibilities of side-stepping the issue through regional instead of state-specific requirements and recasting the restriction to be against power sold out-of-state instead of power produced out-ofstate, a strategy known as 'bundling' (Elefant and Holt, 2011). The motivation for these arguments is to keep state SREC prices high and reward in-state solar power producers.

From the economic literature, Burns and Kang (2012) present evidence that RPS solar carve-outs and associated SREC markets can encourage solar energy uptake. However, lack of guaranteed minimum compensation and uncertainty are major SREC market limitations. They provide a discussion of SREC markets and associated state policies, though they do not identify interstate trade barriers as an additional layer of uncertainty in SREC markets. Other past research into SREC markets and solar uptake has documented positive effects in the residential (Crago and Chernyakhovskiy, 2017) and commercial (Crago and Koegler, 2018; Cohen et al. 2020) solar installation markets. These papers do not consider the impacts of cross-state SREC trade. 
Protectionist policies limiting interstate trade also have surfaced in the broader REC market context (Upton and Snyder, 2017; Rudik, 2018) and have been challenged legally (Elefant and Holt, 2011). A review by Mack et al. (2011) finds that most states with RPS programs have required that a certain amount of renewable energy be produced in-state. They argue that such policies increase volatility of REC markets and increase the cost of renewable energy. State-specific REC regulations also have led to fragmented REC markets with greater price volatility. These outcomes have slowed the development of renewable energy in the U.S. and limited the effectiveness of policies intended to encourage renewable energy generation. Heterogeneity of state RPS programs and REC markets, including eligibility of out-of-state solar energy producers in REC markets, was also discussed by Schmalensee (2011). State policies regarding eligibility of out-of-state RECs include: (not) accepting out-of-state RECs, accepting RECs only from particular geographic regions or Regional Transmission Authorities, discounting out-ofstate RECs, and providing additional credit to in-state RECs. ${ }^{3}$

The economic literature on the role of tradable credits in conjunction with ratio standards in mitigating externalities from energy generation thus far has focused broadly on renewable generation (e.g. McKitrick, 2005; Rudik, 2018; Hollingsworth and Rudik, 2019). Economic analysis of SRECs has been sparse, and only limited attention has been devoted to the examination of interstate trade policies and their economic implications. Rudik (2018) shows that states with high RPS compliance costs (i.e. states that would be purchasers of out-of-state RECs if trade is allowed) may be better off by restricting interstate REC trad- 
ing because trade can worsen local pollution externalities, which can offset the value of compliance cost savings achieved through REC trade. Hollingsworth and Rudik (2019) examine the effect of state RPS requirements on electricity generation from non-renewable sources. They find that as a result of interstate trade of RECs, an increase in a states RPS requirement can decrease the use of nonrenewable resources across states.

In this paper we evaluate the economic outcomes of SREC trade protectionism for the home state of the SREC market. As the legislatures of the states with solar carve-outs are the ones enacting protectionist policies, the most relevant question for this group is whether closing the SREC market to out-of-state solar producers will benefit the state. We extend the prior literature by examining the merits of protectionist interstate SREC trade policy. We explicitly consider the effects of SREC trade restrictions on electricity consumers via rate increases and on increased in-state installation of solar panels, which can provide additional 'green jobs'. We estimate the effects of SREC prices on residential and overall solar capacity additions that takes account of cross-state SREC market access.

This paper is structured as follows. In section 2, we discuss the SREC market data for the U.S. Section 3 provides a graphical and analytical exposition describing the theoretical foundation for the analysis. We explore the effects of protectionist policies on SREC and electricity prices empirically in section 4.1. In section 4.2, we assess the effects of SREC price on solar capacity additions. Thus, we consider and quantitatively assess both the costs of market protectionism in the form of increased compliance costs and electricity prices due to higher SREC 
price and the benefits of the policy in terms of spurring solar investment. Section 5 summarizes and concludes.

\section{State SREC markets}

Table 1 provides details for seven of the nine SREC markets that exist in the U.S. including whether they allow out-of-state facilities to qualify for SRECs through 2015. The recently established Illinois and North Carolina SREC markets are omitted from the analysis because they have low levels of SREC trading activity and lack comparable detail in our source data. As of 2015, two of the seven included markets allowed out-of-state solar facilities to qualify for their SREC programs, while the other five markets only allow in-state solar facilities to earn SRECs $^{4}$. New Jersey, Massachusetts and Delaware have always had closed-off SREC markets since the inception of their solar carve-outs. D.C. and Maryland used to allow out-of-state facilities to qualify for their SREC markets but changed their RPS legislation to limit SREC markets only to in-state, or in the case of D.C., in-district solar facilities.

States enact solar carve-outs to encourage diversification of the generation mix and to support the local solar industry, which they hope will bring green jobs, related economic growth, and a smaller electricity consumption carbon footprint (Gaul and Carley, 2012). The rationale behind closing off an SREC market to out-of-state solar energy producers is to keep the SREC-related incentive to install solar capacity within the state and thus also keep the jobs and economic benefits 
from increased solar investment within the state. However, previous research has shown that solar carve-outs increase the cost of meeting an RPS requirement and that this cost may be borne by electricity consumers (Novacheck and Johnson. 2015).

Figure 1 shows the monthly historical auction prices for SRECs sold in the market of each state for which we have data. ${ }^{5}$ A comparison of these price trends with the information in table 1 reveals that states with open SREC markets, such as PA and $\mathrm{OH}$, generally have lower market prices for SRECs than closed-off states. Indeed, within our price data the average price of an SREC in a closed state is $\$ 290.39$, while the average price in an open state is $\$ 151.67$. A t-test of the difference in means across groups confirms that this difference is statistically significant at the $1 \%$ level.

SREC prices have two implications that suggest a tradeoff for states that decide to close-off their SREC markets. On the one hand, higher SREC prices generate greater economic benefits and job growth from increased in-state solar investment. On the other hand, they may increase the cost of complying with the solar carveout; a cost that may be borne by utility companies and/or ratepayers. The net effect of higher SREC prices is ambiguous and has not been studied.

To link SREC prices with the level of solar installation in each state and year, including states that do not have domestic SREC markets, we construct an effective SREC price variable. This variable represents the price that a solar producer based in a specific state could get for their SRECs in a given year. This price is the highest average annual SREC price in an SREC market that the producer could 
access, based on the availability of SREC markets for that year. ${ }^{6}$ This implies that the effective SREC price in a state with access to multiple SREC markets in a given year is the highest price of those available. ${ }^{7}$

Figure 2 shows the total annual additions to both residential and aggregate solar capacity in the continental U.S., represented in the OpenPV database over the sample period (2004-2015). Solar capacity installations peaked in 2012, while annual residential installations rise steadily. Additionally, figure 2 gives the weighted average SREC price accessible to solar producers across U.S. states in each year. This value is calculated as the effective SREC price that is accessible in each state weighted by the size of the state's electricity market measured in terms of electricity sales. States with no SREC market access are omitted from the calculation of weighted avg. SREC prices. Figure 2 shows that annual capacity additions increase while SREC prices decrease in the post-2008 period. The increased aggregate capacity can be a cause for the decrease in SREC prices. While we expect solar installations to be driven by SREC prices, as alluded to by (Crago and Chernyakhovskiy, 2017; Crago and Koegler, 2018; Cohen et al., 2020), figure 2 implies the possibility of reverse causality between SREC prices and solar installations. 


\section{Theoretical analysis}

\subsection{Graphical exposition}

Figure 3 gives a graphical representation of a host state's SREC market. Demand for SRECS in the short run is set largely by the solar carve-out requirements and is responsive to price, as utilities can bank SRECs as assets, use previous year's SRECs to satisfy the requirement, or self-satisfy the requirement by producing solar power. The downward sloping SREC demand curve reflects decreasing marginal benefits of solar energy generation. A binding RPS solar carve-out requirement implies that each additional unit of solar energy allows for an additional proportional quantity of non-solar generation. If marginal benefits of electricity are diminishing, then the marginal benefits of non-solar power along with solar generation and its associated SRECs are also declining. The supply of SRECs comes from qualified solar producers generating power and receiving SRECs in return. The supply curve slopes upwards as potential solar adopters may be more likely to install a solar unit and begin contributing SRECs to the market when SREC prices are high.

The supply and demand curves in the SREC market are bounded from above due to Solar Alternative Compliance Payments (SACP), whereby utilities can pay a set fee to satisfy the solar carve-out requirement in lieu of purchasing and retiring SRECs. The SACP functions the same way as the general Alternative Compliance Payment (ACP) present in RPS policies for all other renewable generation sources, except that it is specific to solar and that the SACP is often much higher than the 
ACP. Burns and Kang (2012) discuss how the SACP puts a price cap on the market and functions as a safety valve against exorbitant SREC prices. The SREC market is also bounded from below, in theory, by the market price of a REC. The solar carve-outs that establish SREC markets are meant to distinguish solar from other sources of renewable energy and add an additional subsidy for solar resources. However, if the SREC price is low, the SREC can be sold on the REC market.

Figure 3 illustrates a scenario in which a state closes its SREC market to outof-state suppliers. This effectively reduces the supply of SRECs from $S_{S R}$ to $S_{S R}^{\prime}$. As a result, the SREC price increases from $P_{\text {open }}$ to $P_{\text {closed }}$. The increase in price, with static demand, makes the solar carve-out more expensive to satisfy and SREC buyers (i.e. utility companies) lose area ABDC in surplus. The reduction of the utility's surplus corresponds to the increased cost of compliance with the solar carve-out under restricted SREC trade. In the long run, the utility might increase rates to maintain solvency, which could affect the quantity of electricity demanded.

In-state producers of SRECs, i.e. solar PV owners, gain area ABGC in producer surplus due to higher SREC prices and increased generation from $\mathrm{K}$ to $\mathrm{M}$, while out-of-state producers lose EGDF. The deadweight loss from this shift is the shaded triangle CGD, and represents the inability of in-state solar producers to supply SRECs with the same efficiency as the broader group of in-state and out-of-state producers when marginal costs of out-of-state producers are lower than marginal costs of in-state producers. ${ }^{8}$

The magnitude of the increase in in-state solar generation depends on the 
elasticity of demand for SRECs. With perfectly inelastic (vertical) demand, all out-of-state SRECs are replaced by new in-state solar generation. In this case, additional in-state solar generation can effectively increase in-state supply and decrease prices of electricity. On the other hand, a horizontal demand curve would imply that purchase of SRECs decrease by the amount of previously imported SRECs. This outcome is theoretically plausible if in-state non-solar generation decreases in the long run in response to the loss of out-of-state SRECs to maintain compliance with the solar carve-out requirement. In this case, in-state solar generation remains at $\mathrm{K}$, and electricity prices increase to balance supply and demand of electricity. In practice, neither perfectly vertical, nor perfectly horizontal demand for SRECs is likely to hold and the effect of the reduction in out-of-state SREC imports on in-state solar generation and electricity price is ambiguous.

\subsection{Analytical exposition}

In the short run, the demand for electricity can be assumed to be price inelastic. The objectives of the regulator and the utility in the short run are to produce electricity in the most cost-effective way that will satisfy electricity demand in real time. This short-run representation of demand for electricity is often referred to as the "load curve" in electricity literature (Fell and Maniloff, 2018). The load curve identifies the required electricity generation at any time. Electricity demand in this representation can vary over time but is assumed independent of electricity prices. This short run modeling framework has been used in related studies to examine implications of renewable energy credit policies (Hollingsworth and 
Rudik, 2019).

In contrast, we are concerned in this study with long run consumer response to electricity price, illustrated in this section using an analytical model from the perspective of the social planner whose objective is to maximize consumer and producer welfare in the electricity market. Unlike a short run analysis, the demand for electricity in the long run can change as consumers adjust their electricity use depending on electricity prices. Households can adjust their energy use in response to changes in electricity price by purchasing more efficient appliances and by using appliances less frequently (Reiss and White, 2008; Hausman and Trimble, 1984). Hence, our theoretical frame is consistent with a long run analysis where the demand for electricity can respond to electricity prices. Our model is consistent with the objective of long run social welfare maximization from consuming and producing electricity, accounting for decreasing marginal benefits of electricity use. Demand for electricity in this case is downward sloping rather than fixed. ${ }^{9}$

Consider the following social planner's surplus maximization problem in the electricity market. Net benefits are composed of total benefits from consuming electricity $(E)$, minus costs of solar $\left(e_{s}\right)$ and non-solar $\left(e_{0}\right)$ energy generation, and the costs of SRECs purchased from out-of-state solar energy producers $(S)$.

$\max _{\text {w.r.t } E, e_{0}, e_{s}} \int_{0}^{E} D(t) d t-C_{s}\left(e_{s}\right)-C_{0}\left(e_{0}\right)-\mu S$

subject to: 


$$
\begin{gathered}
e_{0}+e_{s} \geq E \\
(\alpha-1) e_{s}+\alpha e_{0}<S
\end{gathered}
$$

Where

$D(E)$ - Demand for E units of electricity

$C_{s}\left(e_{s}\right)$ - Cost of generating $e_{s}$ units of solar electricity

$C_{0}\left(e_{0}\right)$ - Cost of generating $e_{0}$ units of electricity from non-solar sources

$S$ - Units of SRECs purchased from out-of-state

$\alpha$ - RPS solar carve-out requirement as pct. of total generation

$\mu$ - Price of an out-of-state SREC

Equation (2) ensures that total electricity generation from solar and non-solar units meets electricity demand. Equation (3) represents the solar carve-out mandate, which requires that solar generation and purchases of SRECs have to be at least $\alpha$ percent of total electricity generation. The Lagrangian and corresponding first order conditions are as follows. 


$$
\mathcal{L}=\int_{0}^{E} D(t) d t-C_{s}\left(e_{s}\right)-C_{0}\left(e_{0}\right)-\mu S+P\left(E-e_{s}-e_{0}\right)+\phi\left[S-(\alpha-1) e_{s}-\alpha e_{0}\right]
$$

$$
\begin{array}{rrr}
{[E]} & D(E)+P=0 \\
{\left[e_{s}\right]} & -C_{s}^{\prime}\left(e_{s}\right)-P-\phi(\alpha-1)=0 \\
{\left[e_{0}\right]} & -C_{0}^{\prime}\left(e_{0}\right)-P-\phi \alpha=0 \\
{[P]} & E-e_{s}-e_{0}=0 \\
{[\phi]} & S-(\alpha-1) e_{s}-\alpha e_{0}=0
\end{array}
$$

Where $P$ is the shadow price of the electricity balance constraint, and can be interpreted as the marginal benefit of additional electricity. Assuming efficiency, electricity prices should correspond to marginal social benefits. The $\phi$ is the shadow price for out-of-state SREC purchases. Total differentiation of the first order conditions with respect to $S$ gives:

$$
\begin{aligned}
{[E] } & D^{\prime} \frac{\partial E}{\partial S}+\frac{\partial P}{\partial S} & =0 \\
{\left[e_{s}\right] } & -C_{s}^{\prime \prime} \frac{\partial e_{s}}{\partial S}-\frac{\partial P}{\partial S}-\frac{\partial \phi}{\partial S}(\alpha-1) & =0 \\
{\left[e_{0}\right] } & -C_{0}^{\prime \prime} \frac{\partial e_{0}}{\partial S}-\frac{\partial P}{\partial S}-\frac{\partial \phi}{\partial S} \alpha & =0 \\
{[P] } & \frac{\partial E}{\partial S}-\frac{\partial e_{s}}{\partial S}-\frac{\partial e_{0}}{\partial S} & =0 \\
{[\phi] } & 1-(\alpha-1) \frac{\partial e_{s}}{\partial S}-\alpha \frac{\partial e_{0}}{\partial S} & =0
\end{aligned}
$$


The second order conditions in (6) can be expressed in terms of the Bordered Hessian representation as $A H=B$, where $A=\left[\frac{\partial E}{\partial S}, \frac{\partial e_{s}}{\partial S}, \frac{\partial e_{0}}{\partial S}, \frac{\partial P}{\partial S}, \frac{\partial \phi}{\partial S}\right]$ is the vector of derivatives of all endogenous variables w.r.t $S$. $H$ is the Hessian matrix shown below, and $B=[0,0,0,0,0,-1]$.

$$
H=\left[\begin{array}{ccccc}
D^{\prime} & 0 & 0 & 1 & 0 \\
0 & -C_{s}^{\prime \prime} & 0 & -1 & -(\alpha-1) \\
0 & 0 & -C_{0}^{\prime \prime} & -1 & -\alpha \\
1 & -1 & -1 & 0 & 0 \\
0 & -(\alpha-1) & -\alpha & 0 & 0
\end{array}\right]
$$

From Cramer's rule we obtain the effect of SREC imports on electricity shadow price, the marginal value of SRECs, in-state solar generation, and in-state nonsolar generation. $H_{1}$ in (7) is obtained by replacing the fourth column of $H$ with vector $B . H_{2}$ in (8) is obtained by replacing the fifth column of $H$ by $B, H_{3}$ in (9) is obtained by replacing the second column of $H$ by $B$, and $H_{4}$ in $(10)$ is $H$ with the third column replaced by $B$.

$$
\begin{gathered}
\frac{\partial P}{\partial S}=\frac{\operatorname{det}\left(H_{1}\right)}{\operatorname{det}(H)}=\frac{D^{\prime}\left((1-\alpha) C_{0}^{\prime \prime}-\alpha C_{s}^{\prime \prime}\right)}{D^{\prime}-(\alpha-1)^{2} C_{0}^{\prime \prime}-\alpha^{2} C_{s}^{\prime \prime}} \\
\frac{\partial \phi}{\partial S}=\frac{\operatorname{det}\left(H_{2}\right)}{\operatorname{det}(H)}=\frac{C_{0}^{\prime \prime} C_{S}^{\prime \prime}-D^{\prime}\left(C_{0}^{\prime \prime}+C_{S}^{\prime \prime}\right)}{D^{\prime}-(\alpha-1)^{2} C_{0}^{\prime \prime}-\alpha^{2} C_{s}^{\prime \prime}}<0 \\
\frac{\partial e_{s}}{\partial S}=\frac{\operatorname{det}\left(H_{3}\right)}{\operatorname{det}(H)}=\frac{-D^{\prime}-(\alpha-1) C_{0}^{\prime \prime}}{D^{\prime}-(\alpha-1)^{2} C_{0}^{\prime \prime}-\alpha^{2} C_{s}^{\prime \prime}}<0
\end{gathered}
$$




$$
\frac{\partial e_{0}}{\partial S}=\frac{\operatorname{det}\left(H_{4}\right)}{\operatorname{det}(H)}=\frac{D^{\prime}-\alpha C_{S}^{\prime \prime}}{D^{\prime}-(\alpha-1)^{2} C_{0}^{\prime \prime}-\alpha^{2} C_{s}^{\prime \prime}}>0
$$

The denominators in equations (7) through (10) are less than or equal to zero, assuming diminishing marginal benefits of electricity and convexity of solar and non-solar electricity generation costs. However, the sign of the numerator in (7) is ambiguous and hinges on the relative magnitudes of the second order derivatives of the cost functions and on the solar carve-out requirement. On the other hand, the expressions in (8) and (9) are unambiguously negative, which implies that the increase in SREC imports has a negative effect on SREC prices and in-state solar generation, as expected. It can be easily verified using $\left[e_{s}\right]$ and $\left[e_{0}\right]$ first order conditions in (5) that $\phi=C_{S}^{\prime}\left(e_{S}\right)-C_{0}^{\prime}\left(e_{0}\right)$, which implies that the marginal value of SRECs is equal to the difference between marginal costs of non-solar and solar generation.

The result in (7) shows that the effect of SREC trading restrictions on the social marginal benefit of electricity is ambiguous. Increases (decreases) in the shadow price of electricity reflect greater (reduced) scarcity. Our analysis suggests that both outcomes are theoretically possible.

With decreased access to out-of-state SRECs, the utility can increase solar generation, purchase in-state SRECs, or decrease non-solar generation to remain in compliance with the solar carve-out requirement. Increasing in-state solar generation capacity effectively increases in-state electricity supply, thereby decreasing the marginal benefit of electricity. This is similar to the argument that Hollingsworth and Rudik (2019) use to explain why wholesale electricity prices 
might decrease in response to increases in RPS requirements. Conversely, decreases in non-solar generation decrease the in-state supply of electricity and increase the social marginal value of electricity. ${ }^{10}$ Both scenarios, as well as a combination of the two, are theoretically possible in the long run. As a result, the net effect on the marginal social value of electricity from SREC market closure is ambiguous.

Lastly, increases in solar generation contribute to social welfare through additional electricity supply and the potential for additional solar-related jobs, which served as the original impetus for several states to adopt policies restricting out-ofstate SREC purchases. Likewise, decreased non-solar generation decreases social welfare due to lower electricity supply and higher electricity prices and does not deliver intended growth in in-state solar industry.

\section{Empirical analysis}

Based on the comparative static results in section 3.2, we empirically assess the effects of access to out-of-state SRECs on electricity prices, SREC prices, and in-state solar generation. In particular, we examine the effects of market closure on SREC and electricity prices and the effect of increased SREC prices on solar adoption. This section proceeds in two parts. First, we examine the effects of SREC market closure on SREC and electricity prices in section 4.1.

Second, we estimate the effect of changes in effective SREC prices on annual solar capacity installed and the number of installations using data from East- 
ern U.S. states from 2004-2015 in section 4.2. ${ }^{11}$ This effect is assessed for both residential and total solar generation units, where the latter includes residential, commercial, and utility scale solar installations. Research suggests that different actors respond differently to various incentives when it comes to solar adoption (Crago and Chernyakhovskiy, 2017; Crago and Koegler, 2018; Cohen et al., 2020). Quantifying the relationship between SREC prices and solar uptake allows for an assessment of the benefits from SREC market closure to out-of-state solar producers. In-state potential benefits from increased solar generation in response to higher SREC prices include development of the solar industry, direct investment in the state's economy, and the creation of green jobs.

\subsection{Effect of market protectionism on SREC and electricity prices}

In this section we estimate the treatment effect of a protectionist state SREC market policy on the price of SRECs and electricity. The theoretical exposition in section 3.2 suggests that closing the SREC market to credits from out-of-state producers will have a positive effect on SREC prices and can have either a positive or negative effect on electricity prices within the state, depending on the response of utilities. 


\subsubsection{Data and methods for price models}

SREC price data are obtained from SRECtrade.com, which reports monthly average SREC prices in each state. This dataset contains monthly state level observations during periods when a given state had an SREC market, as shown in table 1. State-specific SREC price trends are presented in figure 1, while the weighted average SREC price is shown in figure 2. Both figures show that SREC prices decrease over the sample period, with some exceptions.

Electricity price data are provided by the U.S. Energy Information Administration under the series "Average retail price of electricity." These data report the monthly average end-user price per $\mathrm{kWh}$ across all consumption sectors. The variables in the price models are summarized in table 2 for the seven states with active SREC markets in 2015.

The monthly average SREC price in each state is modeled as a function of the state solar carve-out requirement given as a percentage of retail electricity supply, year and state fixed effects, and an indicator variable that takes a value of one if the state SREC market is closed. Binder et al. (2016) show that SREC prices are determined exogenously to the larger electricity price and REC price system. The authors suggest that the largest factor driving SREC prices is the variation in solar installation costs over time (Binder et al., 2016). These changes are captured by the year fixed effects. The year fixed effects also account for the increasing supply of SRECs, as more qualified solar generators are installed over the sample period, and other factors including growing demand for solar, greater awareness of SREC markets, and greater competition from natural gas. 
The monthly average electricity prices in the states with SREC markets are modeled as functions of state and year fixed effects and the indicator variable for the existence of a protectionist SREC policy or the effective average SREC price in the state. The year fixed effects will account for large-scale swings in electricity markets due to macroeconomic trends while still allowing for identification of the treatment effect of a protectionist policy on SREC prices.

In the case of both SREC and electricity price dependent variables, we use panel data regression techniques at the state level. Random effects (RE) and fixed effects (FE) at the state level are compared for each dependent variable. The null hypotheses that the random effects models are unbiased are rejected, with p-values of 0.0004 and 0.000 for the SREC and electricity price models respectively. ${ }^{12}$ Thus, we present the results from the models with both state and year fixed effects. ${ }^{13}$

For the SREC price analysis, we also use the Tobit model with state and year fixed effects as a secondary specification. This model has the added advantage that it can control for the potential censoring of the SREC price series, as depicted in figure 3. SREC prices are bounded from above at the level of the SACP, and from below by the REC price. ${ }^{14}$ For SREC prices at or above the SACP the utilities would pay the compliance payment and not buy SRECs, thus driving SREC prices back down below the threshold. REC prices serve as the lower bound for SREC prices because SRECs can be sold in the REC market. 


\subsubsection{Results for SREC and electricity prices}

The results from the SREC price models are shown in table 3 , and are consistent across model specifications with respect to the effect of market closure. The year fixed effects indicate that prices were higher in the years when SREC supply was low due to fewer qualified solar generation facilities and higher solar installation costs. We observe that market closure has a positive effect on SREC prices as expected. Finally, the RPS solar carve-out requirement is shown to be positively related to SREC prices, as expected, though the effect is statistically significant only in the Tobit model.

The results of the electricity price models are provided in table 4. In Model A, the SREC market is represented by an indicator for market closure, while in Model B, the average effective SREC price in the state is used. Model A shows a negative treatment effect from SREC market closure on electricity prices. Similarly, Model B shows a negative relationship between SREC prices and electricity prices. This is consistent with the findings in table 3 that SREC market closure leads to increasing SREC prices. Both models show that SREC market closure is associated with lower electricity prices, either directly as in Model A, or indirectly in Model B. Higher SREC prices, due to restriction of out-of-state SRECs, encourage in-state generation of solar energy, which increases supply and decreases the price of electricity. This suggests that higher SREC prices may not be passed through to electricity consumers in the form of higher electricity prices. ${ }^{15}$ The results of a difference in differences model provided in the Appendix also show a negative effect of the Maryland SREC market closure on electricity prices, on av- 
erage. Similar results in this context have been reported elsewhere (Binder et al. 2016) and examinations of the effects of broader RPS requirements on electricity prices have produced both positive (Tra, 2016; Woo et al., 2011) and null effects (Maguire and Munasib, 2018).

\subsection{Effect of SREC price on solar capacity additions}

Having confirmed that SREC market protectionism leads to increases in SREC prices, both analytically and empirically, we now seek to understand the last piece to the puzzle: the effect of SREC price on solar capacity additions.

\subsubsection{Data and methods for solar capacity models}

We use annual state data for the Eastern U.S. from 2004-2015 to explain annual solar capacity additions as a function of SREC prices, state level variables and solar-related policies. The data are summarized in table 5 . The solar capacity data are obtained from the OpenPV database as yearly aggregates of solar installations in each state. The OpenPV database collects information on the PV systems installed in each state from state agencies and aggregators, and covers an estimated $81 \%$ of the U.S. PV installations. ${ }^{16}$

The residential capacity and total capacity variables measure the capacity of residential and total solar installed in a given state and year. The residential installs and total installs variables measure the number of residential and total solar facilities installed in a given state and year, respectively. We model installation fre-

quency and installed capacity separately using the suite of explanatory variables 
shown in table 5. We use OLS and two-part models for estimations of installed capacity, which is a continuous variable with a density spike at zero. Eighty-five of the 324 observations in the sample have a zero value for residential capacity. The two-part model estimates the probability of observing zero values via logit regression, and then the level of the dependent variable conditional on it being non-zero via OLS (Belotti et al., 2015). For the total capacity dependent variable, 52 observations are zero, making the two-part model a valid choice here as well. The residential installs and total installs dependent variables are modeled via Poisson regression. To account for the excess zeros in the count variable models, the zero-inflated Poisson was tested, but was found to be only a weak improvement via the Vuong test $(\mathrm{p}=0.07)$ (Vuong, 1989), with very similar results to the classic Poisson.

All models also include spatial fixed effects at the NERC (North American Electric Reliability Corporation) region level, following previous research documenting the effect of the RPS policy on renewable generation at the NERC region level (Bowen and Lacombe, 2017). ${ }^{17}$ The spatial fixed effects in our models account for policy spillovers and any other similarities in the electricity grid, solar potential, or consumer preferences within NERC regions. The models also contain year fixed effects, which control for federal solar-related policies and the falling price of solar technology over time.

In these models the variable of primary interest is $S R E C$ price $_{t-1}$, which relates the effective price of SRECs in the previous year to solar uptake. The lagged values of SREC price are used to avoid endogeneity. The variable $S R E C$ price $_{t-1}$ 
is the effective SREC price, as described in section 2, and measures the highest average price of SRECs in the markets that solar producers would have had access to based on their state of residence for a given year. Note that in many cases this means that states without solar carve-outs would have access to SREC markets, and would have positive values for the variable SREC price $_{t-1}$. This differs from past studies of solar adoption, wherein only in-state SREC prices were considered (Bauner and Crago, 2015; Crago and Chernyakhovskiy, 2017). Interstate access to SREC markets is defined based on the DSIRE database, SRECtrade.com data, and the GATS tracking ${ }^{18}$ of cross-state quantities of RECs traded. Interstate access to a given market ends when protectionist SREC policies are put into place, turning the out-of-state SREC price variable to zero or the next highest price from another accessible SREC market. This definition of the SREC price variable allows for examination of the cross-state effects of SREC access on solar adoption rates. Such cross-state effects have been identified in the case of general REC markets (Hollingsworth and Rudik, 2019).

The Eastern U.S., defined as states east of the Mississippi River and Washington D.C., is used as a convenient definition of the sample as it includes all states with SREC markets, and all states where solar producers have access to these markets. This scope of analysis limits the effects of variation in unobserved characteristics (e.g. climate, culture, urban design, and economic structure) that would come from also including the Western U.S. states.

In addition to SREC prices, we include a suite of state-level variables shown in table 5 (following Cohen et al., 2020, Crago and Koegler, 2018; Crago and 
Chernyakhovskiy, 2017). GDP per capita and average sales tax variables are used to account for state economic characteristics. State average consumer electricity prices, total electricity sales, and deregulation status characterize the electricity market in each state. Electricity price is a particularly important variable as it impacts the return-on-investment from solar units. Average solar intensity across the state and its standard deviation across months is included as another driver of the return-on-investment from solar installations. Finally, we include policy indicator variables from the DSIRE Database to account for the presence of other major solar-related policies across states. We include a net metering indicator that takes a value of one if the state has a net metering law in place in a given year. Net metering laws allow for excess solar power produced to be sold back into the grid. Similarly, we include an indicator for access policies, which guarantee rights for solar installations, and an indicator for the presence of an RPS requirement. Note that states with SREC markets will also have RPS laws, as SREC markets come from special solar carve-out provisions within RPS.

\subsubsection{Results for solar capacity models}

The results for residential solar in table 6 and total solar in table 7 are provided in terms of average marginal effects. The results show that SREC prices have a strong positive effect on solar adoption across model specifications and dependent variables. An increase in last year's effective SREC price increases annual residential and total solar capacity installed. Similarly, lagged SREC prices have a positive effect on the annual number of both residential and total solar installa- 
tions. Increase in total capacity exceeds the corresponding increase in residential capacity in response to higher SREC prices by a substantial margin. The difference between marginal effects of SREC price on the number of residential and total installations is negligible. This result is reasonable given that an overwhelming number of installations are residential ${ }^{19}$.

We find the expected signs on the electricity price, deregulation and insolation variables, which are all positively correlated with installed solar capacity and the number of installations. We find a consistent positive sign of net metering laws on both residential and total solar capacity installed. Interestingly, RPS policies are shown to have a negative effect on solar installations and capacity installed. This result is expected, as the effect of solar carve-outs within an RPS will be captured by the SREC price variable. States with RPS that do not have a solar carveout incentivize other, cheaper types of renewable generation capacity, which can crowd out new solar installations.

\subsection{Discussion of results}

Combining the results in sections 4.1 and 4.2 we can begin to quantify the effects of closing an SREC market on the host state. The results of the SREC price models (table 3) show that closure of an SREC market to out-of-state solar producers results in a 369 - 385\% increase in SREC prices, depending on the model specification. ${ }^{20}$ This shows that protectionist policies have the potential to cause substantial price increases in SREC markets. Recent history supports this finding, as a 150\% increase in SREC prices was observed in the first six months after 
Pennsylvania closed their SREC market to future out-of-state solar generators in late 2017 (Feldman et al., 2018). In contrast, the state solar requirement, a strong driver of the demand for SRECs, is only shown to have a statistically significant effect on SREC prices in the Tobit model specification of table 3, which might suggest that out-of-state supply of SRECs are a stronger driver of SREC price than in-state demand. This result upholds the finding in Binder et al. (2016) that SREC market prices are largely determined by supply-side factors.

Theoretically, the effect of SREC market closure on electricity prices is ambiguous, as discussed in section 3.2. However, the empirical analysis in section 4.1 shows a consistent negative relationship between SREC market closure and electricity prices. This suggests that utilities do not decrease non-renewable generation and increase electricity prices to satisfy the solar carve-out requirement after losing access to out-of-state SRECs. Instead, in-state solar generation increases and prices for electricity decline as a result of increased supply of electricity and despite any additional costs that may be borne by the utility from purchasing local rather than out-of-state SRECs.

Corroborating this interpretation, in section 4.2 we find that for each dollar increase in SREC price 341 - $374 \mathrm{~kW}$ of total solar capacity is installed in-state, $45-48 \mathrm{~kW}$ of which is residential. The average price of a solar installation in the U.S. is $\$ 3,370 / \mathrm{kW}$ as of 2018 (Barbose and Darghouth, 2019). Combining this figure with the results of the TPM specification from tables 6 and 7 suggests that a $\$ 1$ increase in SREC price leads to an additional investment of $\$ 151,650$ in residential solar and $\$ 1,149,170$ in total solar within the state in the following 
year, on average. At least part of these funds likely flow to out-of-state solar technology producers, and possibly to out-of-state solar installation companies. However, a portion of the additional funds may go to creating regional 'green jobs', as suggested by Yi (2013). These potential benefits can offset the higher cost of satisfying the solar carve-out under higher SREC prices, which depends on the level of the carve-out set by the state legislature. However, we also observe that electricity prices decline despite increases in SREC prices after restricting out-of-state SRECs. This suggests that although higher SREC prices can increase the costs of compliance with the solar carve-out, electricity prices decline.

As an illustrative ex ante cost-benefit analysis case study, take the Pennsylvania (PA) SREC market closure in late 2017 under legislative amendment Act 40. At that time, the PA solar carve-out was $0.3 \%$ of electricity produced in the state, which amounted to 51,000 MWh. PA SREC prices at the time were between $\$ 5$ and $\$ 7$ per MWh. Our estimates in table 3 suggest that prices under market closure would be $369 \%$ higher, at $\$ 18.45$ to $\$ 25.83$, ceterus paribus. The estimated increase in the cost of satisfying the 2017 PA solar carve-out due to market closure is between $\$ 685,950$ and $\$ 960,330 .^{21}$ The estimated benefits from gross investment in additional solar capacity due to the increase in SREC price are between $\$ 2,039,692$ and $\$ 2,855,569$ from the residential sector, ${ }^{22}$ and between $\$ 15,456,336$ and $\$ 21,638,871$ overall. ${ }^{23}$ The estimated gross benefits greatly outweigh the estimated gross costs, although it is uncertain how the gross benefits are distributed. For example, funds may flow to out-of-state providers of solar hardware and installation companies. Nevertheless, this ex ante cost-benefit 
analysis supports the PA legislature's 2017 decision to close the SREC market; the economic benefits of closure likely outweighed the costs. It is also important to recognize that this analysis disregards the out-of-state impacts from restricting SRECs. Some of the increased in-state solar installation may be displacing installations that may have occurred out-of-state if interstate SREC trade were permitted.

\section{Conclusion}

This paper analyzes the economic case for interstate protectionism of SREC markets. These markets arise from special solar carve-outs in state RPS laws, which require that a certain quantity of electricity come from solar resources. Utilities can satisfy these requirements either by expanding solar generation capacity or by buying SRECs from qualified producers of solar power, and thereby incentivize the installation of solar generation, potentially generating green jobs and economic growth. In some cases, qualified solar generation facilities can be located outside of the SREC market's host state. Thus, state SREC markets can incentivize solar installation beyond their own borders. Due to falling SREC prices, some states have considered closing their SREC markets to out-of-state solar producers.

Herein, an analytical framework to understand the potential effects of SREC market closure is developed. The theoretical analysis suggests that market closure should increase in-state SREC prices. However, the theoretical effect of market 
closure on in-state electricity prices is ambiguous, as state utilities can meet the solar carve-out requirement under the new market conditions by either increasing solar generation, purchasing SRECs, or decreasing non-solar generation. This calls into question part of the argument against SREC market closure, as ratepayers may not be faced with higher electricity prices as a result of SREC market closure.

We test these insights empirically using panel data from the seven U.S. states with mature SREC markets. The empirical results related to SREC prices are consistent with the theory. Namely, that SREC market closure unequivocally increases in-state SREC prices. With respect to electricity price, the empirical models consistently find that SREC market closure is associated with lower electricity prices, suggesting that ratepayers do not bear the cost of market closure, on average. We then estimate the effect of SREC price on annual state solar capacity additions. This exercise shows that higher SREC price leads to increases in instate solar capacity additions, which is consistent with existing literature (Crago and Chernyakhovskiy, 2017; Crago and Koegler, 2018; Cohen et al., 2020). Combining this result with the findings related to the decline in electricity prices in response to SREC market closure suggests that in-state supply of solar energy increases in response to the closure of SREC markets.

We observe in an illustrative ex ante cost-benefit analysis of the PA SREC market closure that the economic benefits of market closure likely outweigh the in-state costs. However, our results rely on average effects, and may not accurately represent the conditions in every U.S. state. It is also important emphasize 
that this study examines the merits of protectionist SREC policy from the perspective of a state's decision to close off the SREC markets. We disregard the external implications within the larger region and do not address the issues pertaining to the legality of interstate commerce obstruction. For these reasons, and due to uncertainty as to precisely who benefits from increased in-state solar installation, full welfare analysis for state solar and energy policies remains challenging and should be pursued in greater detail with future research. This hearkens to the burgeoning literature on energy justice (see e.g. Pellegrini-Masini et al., 2020), where issues of cross-subsidization, energy poverty, and progressive tariff structures are being explored. More input into this discussion is needed from economists, especially in eliciting the distribution of costs and benefits from changes to energy policies.

\section{Notes}

${ }^{1}$ The single case to date that has challenged the constitutionality of market closure was in Massachusetts, TransCanada v. Bowles, and was settled out of court, but legal experts believe further litigation on the issue may be on the horizon (Glickstein. 2013).

${ }^{2}$ RECs function similarly to SRECs except that many more renewable energy sources, rather than just solar, can earn RECs.

${ }^{3}$ REC policies across states can also differ in terms of allowed REC banking lengths.

${ }^{4}$ Pennsylvania changed their policy in late 2017 to disallow out-of-state solar producers to sell SRECs into the PA market. This is not represented in our data, which span 2004-2015.

${ }^{5}$ Data are obtained from SRECTrade.com historical auction price time series.

${ }^{6}$ This assumes that solar producers seek to sell their SRECs at the highest price available, 
instead of, e.g., the most easily accessible market.

${ }^{7}$ Since SREC sales occur on an open market, it can happen that no buyer is willing to purchase the SRECS from a producer, and thus this producer may be forced to sell (and certify) their SRECs on another market that they may have access to. While a given state SREC market operates on the basis of supply and demand, SRECs are in some cases differentiated products due to legislative peculiarity. For instance, preference and quotas for in-state SRECS, SRECs certified in a given year, or in a certain location can be written into RPS legislation.

${ }^{8}$ For instance, the in-state producers might have fewer optimal solar siting possibilities, poorer ways of utilizing solar with regard to their home electricity load profiles, or perhaps gain less pleasure from the self-sufficiency and perceived environmentalism of solar production. Previous literature shows all of these concerns are relevant to the household adoption decision (Wang et al. 2017; Haas et al. 1999, Krasko and Doris, 2013.

${ }^{9} \mathrm{~A}$ similar framework can be found in Holland et al. (2009), where the authors assume decreasing marginal benefits of energy use to study the efficiency of low carbon fuel standards.

${ }^{10}$ This formulation assumes that the long run generation of electricity need not be fixed and can adapt to electricity price changes. This assumption is consistent with prior literature documenting consumer response to electricity prices (Hausman and Trimble, 1984, Reiss and White, 2008).

${ }^{11}$ Eastern states are those east of the Mississippi River, including Washington D.C.

${ }^{12}$ The Hausman test is used in the case of the SREC model, while the Mundlak (1978) test is used in the electricity price data due to the poor asymptotic properties of the Hausman test when evaluated for these data.

${ }^{13}$ Additionally, for the electricity price analysis we include a robustness check in the Appendix. The robustness check uses a difference-in-differences specification to estimate the effect of Maryland's SREC market closure on electricity prices, which constitutes a natural experiment that occurred towards the middle of the study period.

${ }^{14} \mathrm{As}$ REC price data is proprietary and only available for a fee, we use the minimum observed SREC price in each state as a proxy for the lower bound.

${ }^{15}$ The decline in electricity prices can also be due to increased availability of cheap natural gas. 
Our specification is capturing this effect via year fixed effects.

${ }^{16}$ Although these data might under-represent installations in states with smaller solar markets (Barbose and Darghouth, 2019), these data have been widely used in prior literature as the best available source regarding U.S. solar installations.

${ }^{17}$ Time-invariant state level variables, such as insolation, preclude the use of state fixed effects, thus NERC level fixed effects are employed. States were categorized into NERC regions based on the 2012 NERC classifications. If a state includes multiple NERC regions it was classified into the region that covered the majority of the state. Classifications based on: https://www.ferc.gov/ market-oversight/mkt-electric/nerc-regions.pdf

${ }^{18}$ GATS is the organization that manages many of the state SREC markets.

${ }^{19}$ In our data, $90 \%$ of installations are residential (891,464 of 991,372 installations).

${ }^{20}$ The average treatment effect of closing the SREC market is calculated following Halvorsen and Palmquist (1980).

${ }^{21} 51,000 \times(18.45-5)=685,950,51,000 \times(25.83-7)=960,330$

${ }^{22} 151,650 \times(18.45-5)=2,039,692,151,650 \times(25.83-7)=2,855,569$

${ }^{23} 1,149,170 \times(18.45-5)=15,456,336,1,149,170 \times(25.83-7)=21,638,871$

\section{References}

Barbose, G. and N. Darghouth (2019). Tracking the sun. Technical report, Lawrence Berkely National Laboratory.

Bauner, C. and C. L. Crago (2015). Adoption of residential solar power under uncertainty: Implications for renewable energy incentives. Energy Policy 86, $27-35$. 
Belotti, F., P. Deb, W. Manning, and E. Norton (2015). Two-part models. The Stata Journal 15(1), 3-20.

Binder, K., J. W. Mjelde, and R. T. Woodward (2016, 05). Price interaction in state-level renewable energy credit trading programs. The Electricity Journal 29, 15-21.

Bowen, E. and D. Lacombe (2017). Spatial dependence in state renewable policy: Effects of renewable portfolio standards on renewable generation within NERC regions. The Energy Journal 38(3), 177-192.

Burns, J. E. and J.-S. Kang (2012). Comparative economic analysis of supporting policies for residential solar PV in the United States: Solar Renewable Energy Credit (SREC) potential. Energy Policy 44, 217-225.

Cohen, J., L. Elbakidze, and R. Jackson (2020). Solar bait: How U.S. states attract solar investments from large corporations. The Energy Journal 41(2), 167-190.

Crago, C. L. and I. Chernyakhovskiy (2017). Are policy incentives for solar power effective? Evidence from residential installations in the Northeast. Journal of Environmental Economics and Management 81, 132-151.

Crago, C. L. and E. Koegler (2018). Drivers of growth in commercial-scale solar PV capacity. Energy Policy 120(C), 481-491.

Elefant, C. and E. Holt (2011). The Commerce Clause and implications for state RPS programs. Technical report, Clean Energy States Alliance. 
Engel, K. (1999). The dormant Commerce Clause threat to market-based environmental regulation: The case of electricity deregulation. Ecology Law Quarterly 26, 243.

Feldman, D., J. Hoskins, and R. Margolis (2018). Solar industry update Q1 2018. Technical report, NREL.

Fell, H. and P. Maniloff (2018). Leakage in regional environmental policy: The case of the regional greenhouse gas initiative. Journal of Environmental Economics and Management 87, 1-23.

Ferrey, S. (2004). Sustainable energy, environmental policy, and states' rights: Discerning the energy future through the eye of the dormant Commerce Clause. NYU Environmental Law Journal 12, 507.

Gaul, C. and S. Carley (2012). Solar set asides and renewable electricity certificates: Early lessons from North Carolina's experience with its renewable portfolio standard. Energy Policy 48, 460-469.

Glickstein, J. (2013). New Yorks proposed solar renewable energy market: Lessons learned from other states SREC markets and recommendations in moving forward. Pace Environmental Law Revies 30(3), 1248-1275.

Goulder, L. H., M. A. C. Hafstead, and I. Williams, Roberton C. (2016, May). General equilibrium impacts of a federal clean energy standard. American Economic Journal: Economic Policy 8(2), 186-218. 
Griffin, W. (2014). Renewable portfolio standards and the dormant Commerce Clause: The case for in- region location requirements. Boston College Environmental Affairs Law Review 41(1), 133-165.

Haas, R., M. Ornetzeder, K. Hametner, A. Wroblewski, and M. Hbner (1999). Socio-economic aspects of the Austrian $200 \mathrm{kWp}$-photovoltaic-rooftop programme. Solar Energy 66(3), 183-191.

Halvorsen, R. and R. Palmquist (1980). The interpretation of dummy variables in semilogarithmic equations. American Economic Review 70(3), 474-75.

Hausman, J. A. and J. Trimble (1984). Appliance purchase and usage adaptation to a permanent time-of-day electricity rate schedule. Journal of Econometrics $26(1), 115-139$.

Havemann, A. (2012). Surviving the Commerce Clause: How Maryland can square its renewable energy laws with the Federal Constitution. Maryland Law Review 71, 848-858.

Holland, S. P., J. E. Hughes, and C. R. Knittel (2009, February). Greenhouse gas reductions under low carbon fuel standards? American Economic Journal: Economic Policy 1(1), 106-46.

Hollingsworth, A. and I. Rudik (2019). External impacts of local energy policy: The case of renewable portfolio standards. Journal of the Association of Environmental and Resource Economists 6(1), 187-213. 
Krasko, V. A. and E. Doris (2013). State distributed PV policies: Can low cost (to government) policies have a market impact? Energy Policy 59(C), 172-181.

Mack, J. H., N. Gianvecchio, M. T. Campopiano, and S. M. Logan (2011). All RECs are local: How in-state generation requirements adversely affect development of a robust REC market. The Electricity Journal 24(4), 8-25.

Maguire, K. and A. Munasib (2018). Price interaction in state-level renewable energy credit trading programs. Environmental and Resource Economics 69, 293-316.

McKitrick, R. (2005). Decentralizing a regulatory standard expressed in ratio or intensity form. The Energy Journal 26(4), 43-51.

Mundlak, Y. (1978). On the pooling of time series and cross section data. Econometrica 46(1), 69-85.

Novacheck, J. and J. X. Johnson (2015). The environmental and cost implications of solar energy preferences in renewable portfolio standards. Energy Policy 86, 250-261.

Pellegrini-Masini, G., A. Pirni, and S. Maran (2020). Energy justice revisited: A critical review on the philosophical and political origins of equality. Energy Research and Social Science 59, 101310.

Reiss, P. C. and M. W. White (2008). What changes energy consumption? Prices and public pressures. The RAND Journal of Economics 39(3), 636-663. 
Rudik, I. (2018). Tradable credit markets for intensity standards. Economic Modelling 72, 202-215.

Schmalensee, R. (2011, 12). Evaluating policies to increase electricity generation from renewable energy. Review of Environmental Economics and Policy 6(1), $45-64$.

Tra, C. I. (2016). Have renewable portfolio standards raised electricity rates? Evidence from U.S. electric utilities. Contemporary Economic Policy 34(1), 184-189.

Upton, G. B. and B. F. Snyder (2017). Funding renewable energy: An analysis of renewable portfolio standards. Energy Economics 66, 205-216.

Vuong, Q. H. (1989). Likelihood ratio tests for model selection and non-nested hypotheses. Econometrica 57(2), 307-333.

Wang, X., Z. Guan, and F. Wu (2017). Solar energy adoption in rural China: A sequential decision approach. Journal of Cleaner Production 168, 1312-1318.

Woo, C., I. Horowitz, J. Moore, and A. Pacheco (2011). The impact of wind generation on the electricity spot-market price level and variance: The Texas experience. Energy Policy 39(7), 3939-3944. Special Section: Renewable energy policy and development.

Yi, H. (2013). Clean energy policies and green jobs: An evaluation of green jobs in U.S. metropolitan areas. Energy Policy 56, 644-652. 


\section{Appendix}

Here we present a robustness check to the main results in table 4 on the effect of SREC market closure on electricity prices. We use the data described in section 4.1 and the natural quasi-experiment of the Maryland SREC market closure at the beginning of 2012 to specify a difference in differences model. The post period is defined to start in January 2012. The D.C. observations are dropped as D.C. also closed their SREC market over this period. The interaction of the Maryland indicator and the post closure indicator is the difference in differences term. The coefficient of this term shows a negative effect of SREC market closure on electricity price, consistent with the results in the main text. 


\section{List of Figures}

$1 \quad$ Monthly average SREC prices by state . . . . . . . . . . . . . . 43

2 Annual solar capacity additions and weighted avg. SREC prices

3 In-state SREC market under market closure . . . . . . . . . . . . 45 
Figure 1: Monthly average SREC prices by state

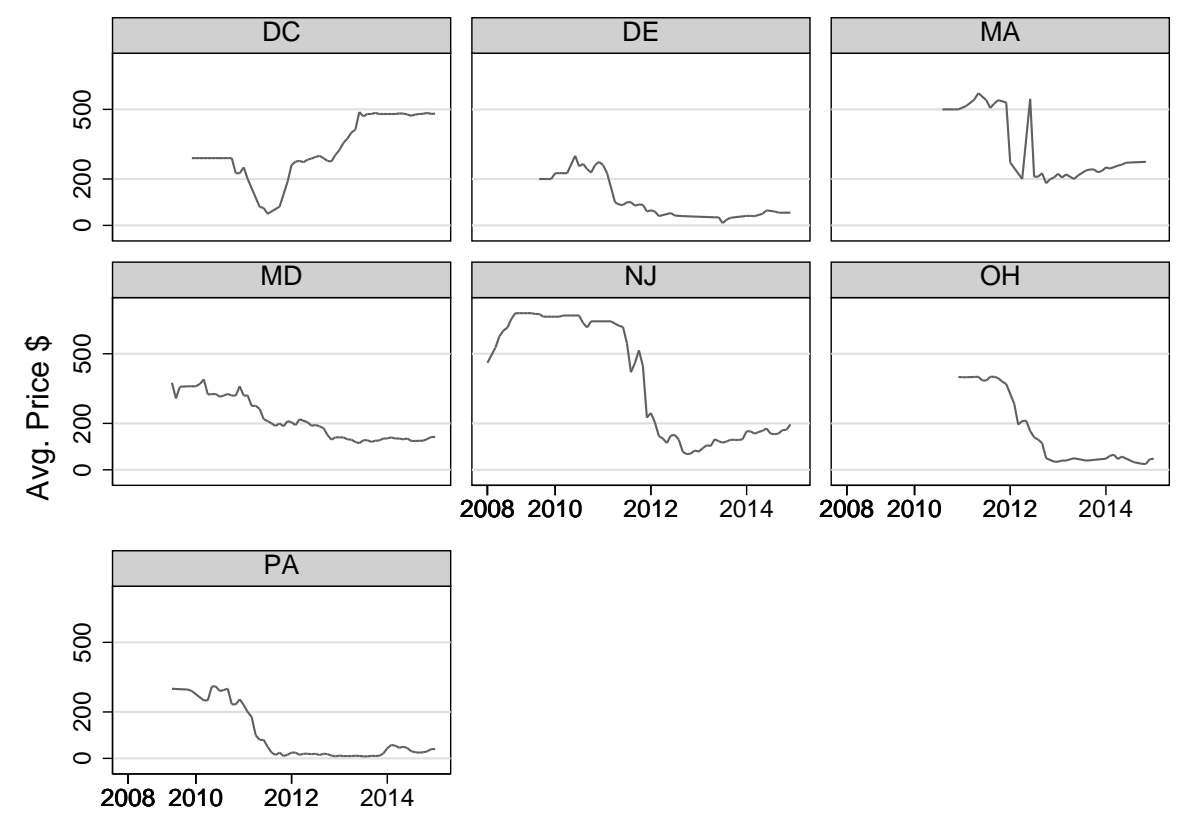


Figure 2: Annual solar capacity additions and weighted avg. SREC prices in the Continental U.S.

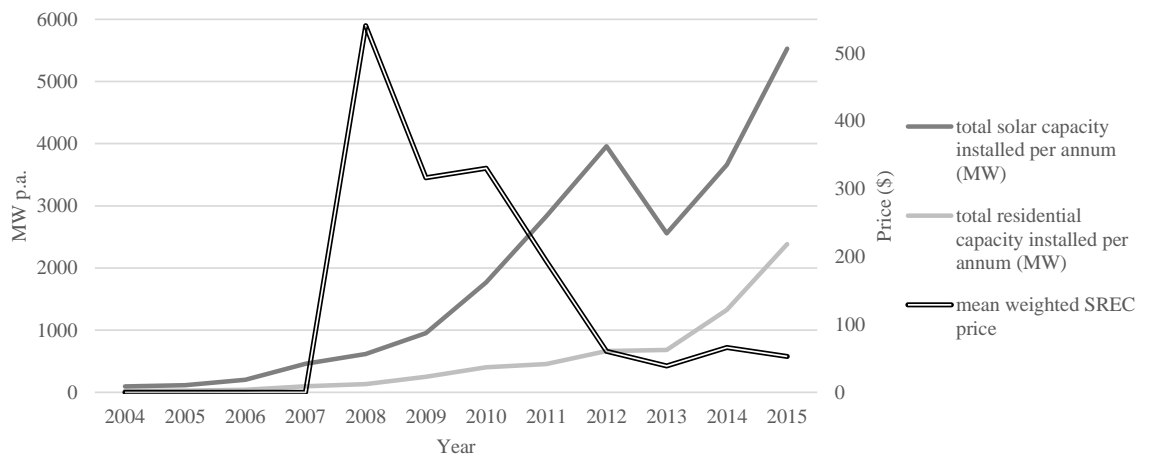


Figure 3: In-state SREC market under market closure

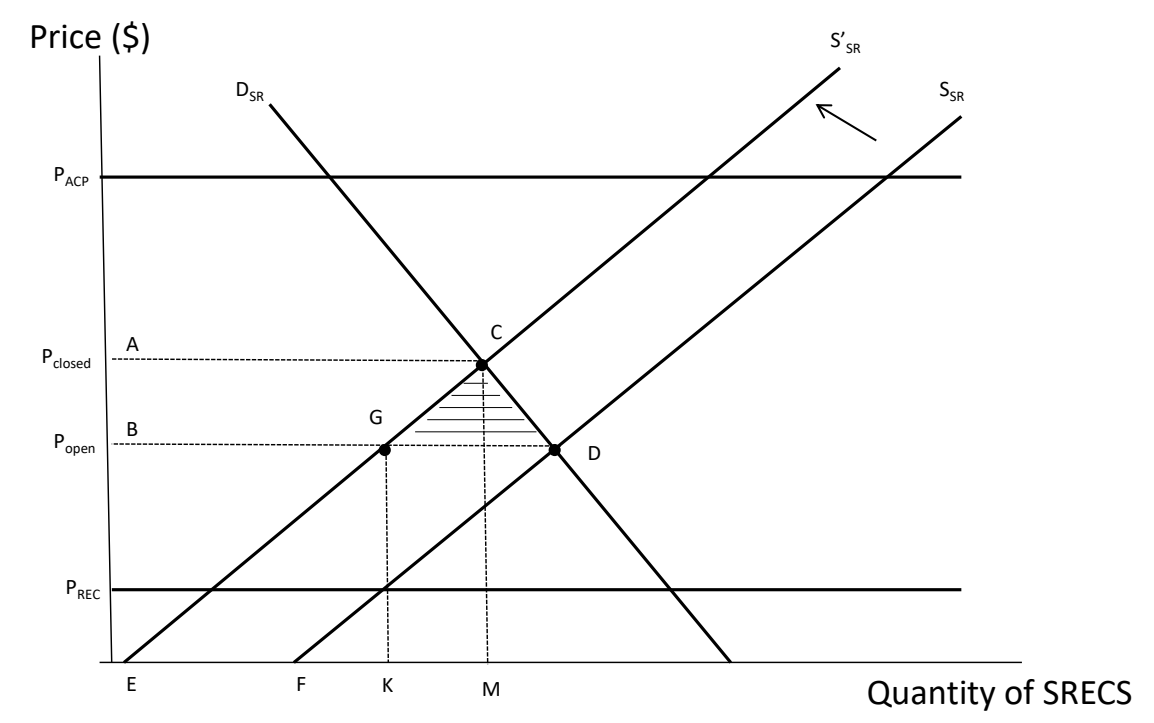




\section{List of Tables}

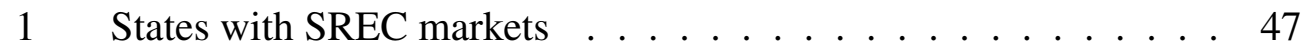

$2 \quad$ Summary statistics and descriptions of variables in price models . 48

3 Estimated effect of protectionist policy on in-state SREC price . . 49

4 Estimated effect of protectionist policy on in-state electricity price 50

$5 \quad$ Summary statistics and descriptions of explanatory variables for solar capacity models . . . . . . . . . . . . 51

6 Average marginal effects of SREC price and other factors on residential solar uptake . . . . . . . . . . . . . . 52

7 Average marginal effects of SREC price and other factors on total solar uptake . . . . . . . . . . . . . . . 53

8 Estimated effect of Maryland's SREC market closure on electricity price ........................ 54 


\section{Tables}

Table 1: States with SREC markets

\begin{tabular}{|c|c|c|c|c|c|c|c|}
\hline State Abbreviation & $\mathbf{O H}$ & PA & $\mathbf{N J}$ & MD & MA & DE & DC \\
\hline $\begin{array}{l}\text { Year SREC market began } \\
\text { Allows out-of-state solar? } \\
\text { Year out-of-state } \\
\text { solar disallowed }\end{array}$ & $\begin{array}{c}2009 \\
\text { Yes }\end{array}$ & $\begin{array}{l}2007 \\
\text { Yes }\end{array}$ & $\begin{array}{c}2005 \\
\text { No } \\
2005\end{array}$ & $\begin{array}{c}2008 \\
\text { No } \\
2011\end{array}$ & $\begin{array}{c}2010 \\
\text { No } \\
2010\end{array}$ & $\begin{array}{c}2008 \\
\text { No } \\
2008\end{array}$ & $\begin{array}{c}2007 \\
\text { No } \\
2011\end{array}$ \\
\hline \multicolumn{8}{|c|}{ Solar carve out (\% of electricity supply) } \\
\hline $\begin{array}{l}2005 \\
2006\end{array}$ & & & $\begin{array}{c}0.01 \\
0.017\end{array}$ & & & & \\
\hline 2007 & & 0.0013 & 0.0393 & & & & 0.005 \\
\hline 2008 & & 0.003 & 0.0817 & 0.005 & & 0.011 & 0.011 \\
\hline 2009 & 0.004 & 0.0063 & 0.16 & 0.01 & & 0.014 & 0.019 \\
\hline 2010 & 0.01 & 0.012 & 0.221 & 0.025 & 0.068 & 0.018 & 0.028 \\
\hline 2011 & 0.03 & 0.0203 & $306 \mathrm{GWh}$ & 0.05 & 0.068 & 0.2 & 0.4 \\
\hline 2012 & 0.06 & 0.0325 & $442 \mathrm{GWh}$ & 0.1 & 0.068 & 0.4 & 0.5 \\
\hline 2013 & 0.09 & 0.051 & $596 \mathrm{GWh}$ & 0.25 & 0.068 & 0.6 & 0.5 \\
\hline 2014 & 0.12 & 0.084 & 2.05 & 0.35 & 0.068 & 0.8 & 0.6 \\
\hline 2015 & 0.12 & 0.144 & 2.45 & 0.5 & 0.3288 & 1 & 0.7 \\
\hline
\end{tabular}

Data compiled from DSIRE database and SRECTrade.com 
Table 2: Summary statistics and descriptions of variables in price models

\begin{tabular}{llcccc}
\hline State & Measure & $\begin{array}{c}\text { Monthly avg. } \\
\text { SREC price (\$) }\end{array}$ & $\begin{array}{c}\text { Solar requirement } \\
\text { (\% of retail electricity sales) }\end{array}$ & $\begin{array}{c}\text { SREC market is } \\
\text { closed (1 = yes) }\end{array}$ & $\begin{array}{c}\text { Monthly avg. electricity } \\
\text { price (cents/kWh) }\end{array}$ \\
\hline DC & Mean & 338.25 & 0.4110 & 0.65 & 12.3404 \\
N=57 & Std. Dev. & 125.20 & 0.2100 & 0.48 & 0.7137 \\
\hline DE & Mean & 121.71 & 0.3307 & 1.00 & 11.4526 \\
N=43 & Std. Dev. & 90.81 & 0.2936 & 0.00 & 0.4865 \\
\hline MA & Mean & 326.83 & 0.0680 & 1.00 & 14.3554 \\
N=37 & Std. Dev. & 142.20 & 0.0000 & 0.00 & 0.8203 \\
\hline MD & Mean & 214.54 & 0.1500 & 0.55 & 12.0177 \\
N=65 & Std. Dev. & 90.12 & 0.1344 & 0.50 & 14.0816 \\
\hline NJ & Mean & 385.56 & 0.6705 & 0.00 & 0.7908 \\
N=76 & Std. Dev. & 247.29 & 0.6422 & 0.00 & 9.2264 \\
\hline OH & Mean & 179.46 & 0.0710 & 0.00 & 0.3931 \\
N=39 & Std. Dev. & 155.82 & 0.0363 & 0.00 & 10.1121 \\
\hline PA & Mean & 88.57 & 0.0409 & 0.00 & 0.3751 \\
N=62 & Std. Dev. & 107.71 & 0.0292 & 0.60 & 12.0452 \\
\hline Total & Mean & 243.65 & 0.2801 & 0.49 & 1.8036 \\
N=379 & Std. Dev. & 187.80 & 0.3950 & & \\
\hline Sample is monthly observations of all states shown in table 1 from 2004-2015, including D.C. & & & \\
& & & & & \\
\hline
\end{tabular}

Sample is monthly observations of all states shown in table 1 from 2004-2015, including D.C. 
Table 3: Estimated effect of protectionist policy on in-state SREC price

\begin{tabular}{lcccc}
\hline & \multicolumn{2}{c}{ FE OLS } & \multicolumn{2}{c}{ FE Tobit } \\
Variable & Coefficient & Std. Err. & Coefficient & Std. Err. \\
\hline SREC market is closed & $1.546^{* *}$ & $(0.552)$ & $1.579^{* * *}$ & $(0.110)$ \\
Solar requirement & 0.272 & $(0.196)$ & $0.296^{* *}$ & $(0.110)$ \\
(\% of retail electricity sales) & & & & \\
yr2008 & $1.632^{* * *}$ & $(0.343)$ & 3.430 & $(7.91)$ \\
yr2009 & $1.971^{* * *}$ & $(0.321)$ & $2.010^{* * *}$ & $(0.274)$ \\
yr2010 & $1.914^{* * *}$ & $(0.303)$ & $1.959^{* * *}$ & $(0.260)$ \\
yr2011 & $1.229^{* *}$ & $(0.366)$ & $1.272^{* * *}$ & $(0.253)$ \\
yr2012 & 0.037 & $(0.340)$ & 0.041 & $(0.247)$ \\
yr2013 & -0.255 & $(0.269)$ & -0.253 & $(0.247)$ \\
yr2014 & 0.027 & $(0.077)$ & 0.029 & $(0.246)$ \\
Constant & $4.959^{* * *}$ & $(0.363)$ & $4.987 * * *$ & $(0.363)$ \\
N & 379 & & 379 & \\
adj. R-sq & 0.657 & & & \\
\hline
\end{tabular}

${ }^{*} p<0.05,{ }^{* *} p<0.01,{ }^{* * *} p<0.001$

Dependent variable is the natural log of avg. in-state SREC price in a given month/year.

2015 is the omitted year dummy variable. Both models contain state fixed effects. 
Table 4: Estimated effect of protectionist policy on in-state electricity price

\begin{tabular}{lcccc}
\hline & \multicolumn{2}{c}{ Model A } & \multicolumn{2}{c}{ Model B } \\
Variable & Coefficient & Std. Err. & Coefficient & Std. Err. \\
\hline SREC market is closed & $-0.0429^{* * *}$ & $(0.017)$ & - & \\
SREC price & - & & $-0.0001^{* *}$ & $(0.000039)$ \\
yr2008 & 0.004 & $(0.013)$ & $0.039^{* *}$ & $(0.013)$ \\
yr2009 & 0.009 & $(0.021)$ & $0.054^{* *}$ & $(0.022)$ \\
yr2010 & 0.015 & $(0.019)$ & $0.054^{* * *}$ & $(0.013)$ \\
yr2011 & -0.023 & $(0.021)$ & 0.004 & $(0.013)$ \\
yr2012 & $-0.051^{* * *}$ & $(0.013)$ & $-0.054^{* * *}$ & $(0.007)$ \\
yr2013 & $-0.041^{* *}$ & $(0.013)$ & $-0.044^{* * *}$ & $(0.011)$ \\
yr2014 & -0.007 & $(0.01)$ & -0.007 & $(0.009)$ \\
Constant & $2.523^{* * *}$ & $(0.019)$ & $2.510^{* * *}$ & $(0.014)$ \\
$\mathrm{N}$ & 379 & & 379 & \\
adj. R-sq & 0.327 & & 0.334 & \\
\hline${ }^{*} p<0.05,{ }^{* *} p<0.01,{ }^{* * *} p<0.001$ \\
Dependent variable is the natural log of avg. in-state electricity price in a given month/year \\
across all types of customers. \\
2015 is the omitted year dummy variable. Both models contain state fixed effects.
\end{tabular}


Table 5: Summary statistics and descriptions of explanatory variables for solar capacity models

\begin{tabular}{|c|c|c|c|c|c|}
\hline $\begin{array}{l}\text { Independent } \\
\text { Variables: }\end{array}$ & Description & Mean & Std. Dev. & Min & Max \\
\hline SREC $_{\text {price }}{ }_{t-1}$ & SREC avg. effective* price from previous year $(\$)$ & 54.72 & 122.11 & 0 & 663.38 \\
\hline GDP per capita & GDP per capita in $2009 \$$ & 51072.10 & 23901.31 & 30509 & 170687 \\
\hline elec. sales & sales to customers in 1000's mwh & 80085.06 & 53222.83 & 5496.51 & 235599.4 \\
\hline sales tax & sales tax in percent & 5.24 & 1.74 & 0 & 7 \\
\hline elec. Price & avg price cents/kwh & 10.15 & 3.03 & 4.63 & 18.07 \\
\hline deregulation & $=1$ if the state/year has a deregulated electricity market & 0.47 & 0.50 & 0 & 1 \\
\hline insolation & NREL direct normal solar resource in $\mathrm{kwh} / \mathrm{sq} \mathrm{m} /$ day & 4.08 & 0.32 & 3.63 & 4.79 \\
\hline insolation s.d. & std. dev. of monthly average insolations over they year & 0.70 & 0.25 & 0.40 & 1.32 \\
\hline net metering & was program present in this state/year, $1=$ yes & 0.47 & 0.50 & 0 & 1 \\
\hline$R P S$ program & was program present in this state/year, $1=$ yes & 0.54 & 0.50 & 0 & 1 \\
\hline Access policy & was program present in this state/year, $1=$ yes & 0.25 & 0.43 & 0 & 1 \\
\hline$n e r c \_r f c$ & & 0.26 & 0.44 & 0 & 1 \\
\hline nerc_serc & These ore fixed effects the NFPC region lew & 0.41 & 0.49 & 0 & 1 \\
\hline nerc Jmro & Inese are ixed elrects at the NEKC region lever & 0.07 & 0.26 & 0 & 1 \\
\hline nerc $f r c c$ & & 0.04 & 0.19 & 0 & 1 \\
\hline \multicolumn{6}{|l|}{$\begin{array}{l}\text { Dependent } \\
\text { Variables: }\end{array}$} \\
\hline total capacity & capacity installed in this state/year $(\mathrm{kW})$ & 18264.9 & 76184.1 & 0 & 792746.7 \\
\hline total installs & number of installs in this state/year & 716.4 & 2613.3 & 0 & 31670 \\
\hline residential capacity & residential capacity installed in this state/year $(\mathrm{kW})$ & 5977.3 & 21805.8 & 0.064 & 230493.8 \\
\hline residential installs & number of residential installs in this state/year & 813.7 & 2837.3 & 1 & 31072 \\
\hline
\end{tabular}


Table 6: Average marginal effects of SREC price and other factors on residential solar uptake

\begin{tabular}{|c|c|c|c|c|c|c|}
\hline \multirow[b]{2}{*}{ Variable } & \multicolumn{2}{|c|}{$\begin{array}{c}\text { Residential solar } \\
\text { Capacity installed }(\mathrm{kW}) \\
\text { TPM }\end{array}$} & \multicolumn{2}{|c|}{$\begin{array}{c}\text { Residential solar } \\
\text { Capacity installed }(\mathrm{kW}) \\
\text { OLS }\end{array}$} & \multicolumn{2}{|c|}{$\begin{array}{c}\text { Number of } \\
\text { residential solar installs } \\
\text { Poisson }\end{array}$} \\
\hline & Coefficient & Std. Err & Coefficient & Std. Err & Coefficient & Std. Err \\
\hline SREC $_{\text {price }} t-1$ & $44.66^{* * *}$ & $(16.63)$ & $48.45^{* * *}$ & (18.32) & $1.533 * * *$ & $(0.338)$ \\
\hline GDP per capita & -0.00988 & $(0.0815)$ & -0.0518 & $(0.085)$ & $0.0312 * * *$ & $(0.006)$ \\
\hline elec. sales & 0.0490 & $(0.0416)$ & 0.0614 & $(0.041)$ & $0.0195 * * *$ & $(0.003)$ \\
\hline sales tax & 979.3 & $(683.9)$ & $1287.1^{*}$ & $(669.7)$ & -42.36 & $(35.25)$ \\
\hline elec. Price & $1699.9 *$ & $(983.0)$ & $2259.3^{* *}$ & (1026.2) & $109.9 * * *$ & (40.69) \\
\hline deregulation & 1899.6 & $(2067.0)$ & 2646.8 & $(2065.1)$ & -426.0 & $(356.9)$ \\
\hline insolation & $10633.1 * *$ & $(4987.7)$ & $7451.3^{*}$ & (4484.1) & -129.7 & $(756.3)$ \\
\hline insolation s.d. & -4151.7 & $(3592.7)$ & $-8412.7 * * *$ & (3097.7) & $-5566.4 * * *$ & (1228.6) \\
\hline net metering & 7533.6 & $(4783.8)$ & 8074.0 & (4944.3) & $212.8^{*}$ & $(127.2)$ \\
\hline RPS & $-9095.8 * * *$ & (2082.9) & $-11057.8 * * *$ & (2580.6) & -306.0 & (199.4) \\
\hline Access policy & -1787.3 & $(2146.4)$ & -2077.0 & (2361.3) & -149.3 & (194.1) \\
\hline 3rd party fin. & $-7292.4 * *$ & $(3645.9)$ & $-7285.6^{*}$ & (3761.1) & -168.3 & (123.3) \\
\hline nerc_rfc & $-9544.8 * *$ & $(4724.5)$ & -8755.0 & (5595.9) & $-926.9 * * *$ & (241.9) \\
\hline nerc_serc & $-17944.3^{* *}$ & $(7189.5)$ & $-17666.0^{* *}$ & (7879.1) & $-5292.8 * * *$ & (730.9) \\
\hline nerc_mro & 919.1 & $(5455.2)$ & 5305.8 & $(6594.4)$ & 1075.8 & $(682.7)$ \\
\hline nerc_frcc & $-34729.8 * * *$ & (11808.4) & $-34597.5 * * *$ & (12581.6) & $-4780.6 * * *$ & (993.8) \\
\hline year 2005 & -686.3 & $(1983.8)$ & -699.2 & $(2037.4)$ & 13.10 & $(40.92)$ \\
\hline year 2006 & -567.6 & (2089.9) & -2287.0 & $(2430.0)$ & 48.72 & (37.48) \\
\hline year 2007 & 510.2 & $(2108.2)$ & -1650.6 & $(2508.3)$ & 42.02 & $(40.01)$ \\
\hline year 2008 & -270.0 & $(2817.7)$ & -3145.1 & (3423.3) & $87.61^{*}$ & $(50.50)$ \\
\hline year 2009 & -52.82 & (3933.2) & -3133.6 & (4111.2) & $225.5^{*}$ & $(122.7)$ \\
\hline year 2010 & -8445.3 & (6188.8) & -9339.3 & $(5822.3)$ & $188.1^{* *}$ & (73.99) \\
\hline year 2011 & -6691.2 & $(5849.1)$ & -9201.3 & $(6180.2)$ & $250.6 * * *$ & (71.62) \\
\hline year 2012 & -547.7 & $(4758.7)$ & -2690.8 & (4972.4) & $545.4 * * *$ & $(86.64)$ \\
\hline year 2013 & 2469.1 & (4019.2) & -396.2 & $(4345.0)$ & $801.7 * * *$ & $(170.0)$ \\
\hline year 2014 & 5453.2 & $(4802.2)$ & 3909.7 & $(5682.7)$ & $1245.8 * * *$ & (244.6) \\
\hline year 2015 & $13794.3 * *$ & (6907.9) & $12554.3 *$ & $(7562.4)$ & $2141.1 * * *$ & $(277.5)$ \\
\hline $\mathrm{N}$ & 324 & & 324 & & 324 & \\
\hline adj. R-sq & 0.34 & & 0.35 & & & \\
\hline Psuedo R-sq & & & & & 0.92 & \\
\hline
\end{tabular}

Sample contains all states East of the Mississippi river and Washington D.C. from 2004-2015.

$* p<0.05, * * p<0.01, * * * p<0.001$ 
Table 7: Average marginal effects of SREC price and other factors on total solar uptake

\begin{tabular}{|c|c|c|c|c|c|c|}
\hline \multirow[b]{2}{*}{ Variable } & \multicolumn{2}{|c|}{$\begin{array}{c}\text { Total solar } \\
\text { Capacity installed }(\mathrm{kW}) \\
\text { TPM }\end{array}$} & \multicolumn{2}{|c|}{$\begin{array}{c}\text { Total solar } \\
\text { Capacity installed }(\mathrm{kW}) \\
\text { OLS }\end{array}$} & \multicolumn{2}{|c|}{$\begin{array}{c}\text { Number of } \\
\text { solar installs } \\
\text { Poisson }\end{array}$} \\
\hline & Coefficient & Std. Err & Coefficient & Std. Err & Coefficient & Std. Err \\
\hline SREC $_{\text {price }} t-1$ & $340.7 * * *$ & (90.19) & $373.8 * * *$ & (101.0) & $1.695 * * *$ & $(0.359)$ \\
\hline GDP per capita & -0.412 & $(0.259)$ & $-0.492 *$ & $(0.268)$ & $0.0234 * * *$ & $(0.00644)$ \\
\hline elec. sales & 0.0569 & $(0.0835)$ & 0.0715 & $(0.0821)$ & $0.0170 * * *$ & $(0.00326)$ \\
\hline sales tax & $5309.1 * * *$ & $(1869.0)$ & $6521.4^{* * *}$ & (2047.2) & -0.439 & $(35.39)$ \\
\hline elec. Price & $7005.7 * *$ & $(3562.9)$ & $8463.7 * *$ & (3931.4) & $137.0 * * *$ & (53.11) \\
\hline deregulation & $16601.4 * *$ & $(8322.7)$ & $17408.8^{* *}$ & (8816.2) & 80.50 & (392.5) \\
\hline insolation & $45971.4 * *$ & (18732.5) & $41902.0 * *$ & (18095.9) & -526.9 & (713.5) \\
\hline insolation s.d. & -19228.7 & (12364.9) & $-32871.1 * * *$ & (12670.8) & $-4371.6 * * *$ & (1177.4) \\
\hline net metering & $25545.2 * *$ & (11832.5) & $27421.6^{* *}$ & (12155.2) & 176.7 & (154.6) \\
\hline RPS & $-50221.2 * * *$ & (13916.2) & $-55251.2 * * *$ & (14715.2) & $-323.8^{*}$ & (182.5) \\
\hline Access policy & -2017.1 & $(7604.3)$ & -2836.9 & $(7862.0)$ & 170.3 & (298.4) \\
\hline nerc_rfc & -31236.3 & (19783.5) & -28230.4 & $(22737.3)$ & $-1042.0^{* * *}$ & (295.2) \\
\hline nerc_serc & $-62729.1 * *$ & $(25835.5)$ & $-65034.3 * *$ & (28319.5) & $-4197.2 * * *$ & (859.3) \\
\hline nerc_mro & 20009.0 & $(24675.2)$ & 31615.4 & $(28638.6)$ & $1189.6^{* *}$ & (521.9) \\
\hline nerc_frcc & $-101691.9 * * *$ & (33567.3) & $-105218.3^{* * *}$ & (34948.7) & $-3578.8^{* * * *}$ & $(1192.5)$ \\
\hline year 2005 & 3092.3 & $(8399.2)$ & -281.4 & $(7238.8)$ & 12.40 & $(59.74)$ \\
\hline year 2006 & -896.0 & $(8161.2)$ & -5500.1 & $(8015.3)$ & 72.26 & (57.12) \\
\hline year 2007 & 3824.2 & (8399.0) & -1095.9 & $(8410.4)$ & 71.40 & (49.03) \\
\hline year 2008 & 1151.2 & (11053.9) & -5785.9 & (10768.5) & $135.0^{* * *}$ & (64.00) \\
\hline year 2009 & -2297.4 & (13322.2) & -8816.0 & (12719.7) & $287.3^{* *}$ & (145.2) \\
\hline year 2010 & $-57858.6 * *$ & $(25045.3)$ & $-59452.6 * *$ & (24105.6) & $247.5^{* *}$ & (102.8) \\
\hline year 2011 & $-39796.7 *$ & (22027.5) & $-44467.0 * *$ & (22101.0) & $337.9 * * *$ & (94.76) \\
\hline year 2012 & 8499.9 & (19045.8) & 2807.3 & (19344.4) & $727.9 * * *$ & (104.2) \\
\hline year 2013 & 14824.9 & $(16910.0)$ & 8650.7 & (17672.3) & $928.7 * * *$ & (180.4) \\
\hline year 2014 & 9716.8 & (17720.4) & 8531.8 & (19738.1) & $1248.3^{* * *}$ & (259.2) \\
\hline year 2015 & 11560.8 & (13939.8) & 2725.3 & (16529.9) & $2115.1 * * *$ & (287.3) \\
\hline $\mathrm{N}$ & 324 & & 324 & & 324 & \\
\hline adj. R-sq & 0.48 & & 0.49 & & & \\
\hline Psuedo R-sq & & & & & 0.91 & \\
\hline
\end{tabular}

Sample contains all states East of the Mississippi river and Washington D.C. from 2004-2015. $* p<0.05, * * p<0.01, * * * p<0.001$ 
Table 8: Estimated effect of Maryland's SREC market closure on electricity price

\begin{tabular}{|c|c|c|}
\hline & \multicolumn{2}{|c|}{ Diff in Diff Model } \\
\hline & Coefficient & Std. Err. \\
\hline Post 2011 & $0.649 * * *$ & $(0.118)$ \\
\hline MD * post 2011 & $-0.709 * * *$ & (0.119) \\
\hline MD & $2.518 * * *$ & $(0.00869)$ \\
\hline $\mathrm{DE}$ & - & \\
\hline MA & $2.207 * * *$ & (0.0998) \\
\hline NJ & $2.336 * * *$ & $(0.0688)$ \\
\hline $\mathrm{OH}$ & $1.772 * * *$ & $(0.0976)$ \\
\hline PA & $1.926 * * *$ & $(0.0850)$ \\
\hline $\mathrm{N}$ & 322 & \\
\hline adj. R-sq & 0.882 & \\
\hline
\end{tabular}

